\title{
Effect of sodium bicarbonate on aspirin-induced damage and potential difference changes in human gastric mucosa
}

\author{
BRUCE K BOWEN, WILLIAM J KRAUSE, KEVIN J IVEY
}

British Medical fournal, 1977, 2, 1052-1055

\section{Summary}

Two aspirin tablets in $100 \mathrm{ml}$ fluid will produce microscopical damage to the human stomach. A study was performed to determine whether a small amount of sodium bicarbonate (equivalent to one-third of a teaspoonful of baking soda) could protect against this damage. Sequential gastric biopsy specimens were taken from 15 healthy subjects before, during, and after intragastric instillation of one of the following isotonic solutions: saline; sodium bicarbonate; $600 \mathrm{mg}$ aspirin suspended in sodium bicarbonate; and aspirin suspended in saline. On a separate day the same solutions were instilled, but gastric transmucosal potential differences were monitored. Light microscopy and scanning electron microscopy of the biopsy specimens showed occasional mucous degranulation of mucosal surface cells, but no cell damage during instillation of sodium bicarbonate. Light microscopy studies 10 minutes after aspirin in saline showed damage in $20 \%$ of surface cells, with focal areas of cellular disruption and microscopic erosions, but only $3.4 \%$ of cells were damaged after aspirin in bicarbonate and there were no erosions. Electron microscopy showed a damaged honeycombed appearance of surface epithelium after aspirin in saline and a normal cobblestone appearance after aspirin in bicarbonate. Aspirin dissolved in bicarbonate failed to induce the usual fall in potential difference.

These findings indicate that sodium bicarbonate in amounts equivalent to one-third of a teaspoonful of baking soda protects the gastric mucosa against aspirininduced damage and prevents the usual fall in potential difference after aspirin.

\section{Introduction}

Aspirin damages gastric mucosa: Baskin et al have shown changes (ranging from microscopic erosions to focal cell disruption) 10 minutes after ingestion of two aspirins in man. Scanning electron microscopy showed that the loss of normal cell apices produced a honeycombed appearance of the surface between erosions. Davenport ${ }^{2}$ showed in animals that the amount of aspirin-induced damage, as measured by gastric bleeding, was proportional to the amount of acid present. And gastrointestinal bleeding in man decreased when aspirin was delivered to the stomach at a $\mathrm{pH}$ above $4 \cdot 5 \cdot^{3-5}$ Histological examination of the stomach was not performed in any of these studies.

Our study aimed to determine by direct assessment whether a small amount of sodium bicarbonate (equivalent to one-third of a teaspoonful of baking soda) would adequately protect the

Departments of Medicine and Anatomy, Harry S Truman Veterans Administration Hospital and University of Missouri School of Medicine, Columbia, Missouri 65201

BRUCE K BOWEN, BA, AGA, summer research fellow

WILLIAM J KRAUSE, PHD,

KEVIN J IVEY, MD, FACP, physician human stomach against aspirin damage. We also wanted to determine whether this amount of bicarbonate could prevent an aspirin-induced fall in the potential difference of the gastric mucosa.

\section{Subjects and methods}

Thirty-four studies were carried out on separate days in fifteen healthy fasting volunteers (13 men, two women) aged 19-25 years. Informed consent was obtained before each study in accordance with the principles of the Declaration of Helsinki. The project was approved by the institutional human experimentation committee.

\section{POTENTIAL DIFFERENCE}

Gastric potential difference was measured by methods previously described. ${ }^{16}$ Polyethylene tube electrodes filled with $\mathrm{KCl}$ in agar were placed in a peripheral vein and the fundus of the stomach Potential difference was recorded continuously on a strip chart recorder. Values were calculated using the mean $\pm S E$ of consecutive values measured every three minutes during each study period.

At the beginning of the study, fasting gastric contents were aspirated and the stomach washed with isotonic saline ( $\mathrm{pH}$ 5.9). After aspiration $100 \mathrm{ml}$ isotonic saline was instilled intragastrically and recordings made over the next 15 minutes to establish a baseline potential difference value. Gastric contents were then aspirated and solutions instilled intragastrically in the following order.

Study $1-100 \mathrm{ml}$ of isotonic saline was instilled and aspirated at the end of 30 minutes (period 1). Then $600 \mathrm{mg}$ of powdered acetylsalicylic acid (equivalent to two tablets of aspirin) suspended in $100 \mathrm{ml}$ of saline ( $\mathrm{pH} 2 \cdot 3$ ) was introduced for 30 minutes and aspirated (period 2). Finally, $100 \mathrm{ml}$ of isotonic saline was again instilled for 30 minutes (period 3)

Study 2-100 $\mathrm{ml}$ of isotonic sodium bicarbonate (pH 8.5, mean sodium concentration $165 \pm 7 \mathrm{mmol}(\mathrm{mEq}) / 1$ ) was instilled and aspirated at the end of 30 minutes (period 1). Then $600 \mathrm{mg}$ of acetylsalicylic acid dissolved in $100 \mathrm{ml}$ of sodium bicarbonate $(\mathrm{pH} 7 \cdot 4$, mean sodium concentration $168 \pm 10 \mathrm{mmol} / 1$ ) was introduced and aspirated at the end of 30 minutes (period 2). The amount of sodium bicarbonate in $100 \mathrm{ml}$ of solution was equivalent to about one-third of a teaspoon of ordinary baking soda with a neutralising capacity of about $18 \mathrm{mmol} .^{7}$ Finaily, $100 \mathrm{ml}$ of isotonic sodium bicarbonate was instilled for 30 minutes (period 3).

Gastric $\mathrm{pH}$ was determined on all aspirates using a Beckman $\mathrm{pH}$ meter.

\section{GASTRIC BIOPSY}

Studies 1 and 2 were repeated in all subjects after a delay of at least one week, but this time biopsy specimens of the gastric fundic mucosa were taken before, during, and after aspirin administration. Sequential biopsies were obtained using a Quinton hydraulic biopsy

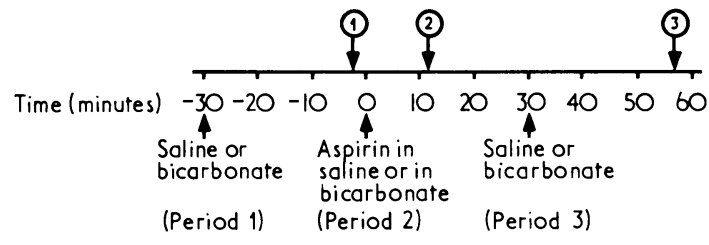

FIG 1-Time scale for each study. Arrows refer to start of each period in either study 1 (aspirin in saline) or study 2 (aspirin in bicarbonate). Numbered circles represent biopsies. 
tube (Quinton Instruments, Seattle, Washington) positioned by fluoroscopic guidance in the gastric fundic mucosa. ${ }^{1}$ Duplicate biopsy specimens (one for light and transmission electron microscopy, the other for scanning electron microscopy) were obtained at the end of period $1 ; 10$ minutes after instillation of aspirin in solution in period 2 ; and 60 minutes after aspirin instillation, at the end of period 3 (fig 1). In an additional three subjects (study 3) separate biopsy studies were conducted using sodium bicarbonate only in all three periods.
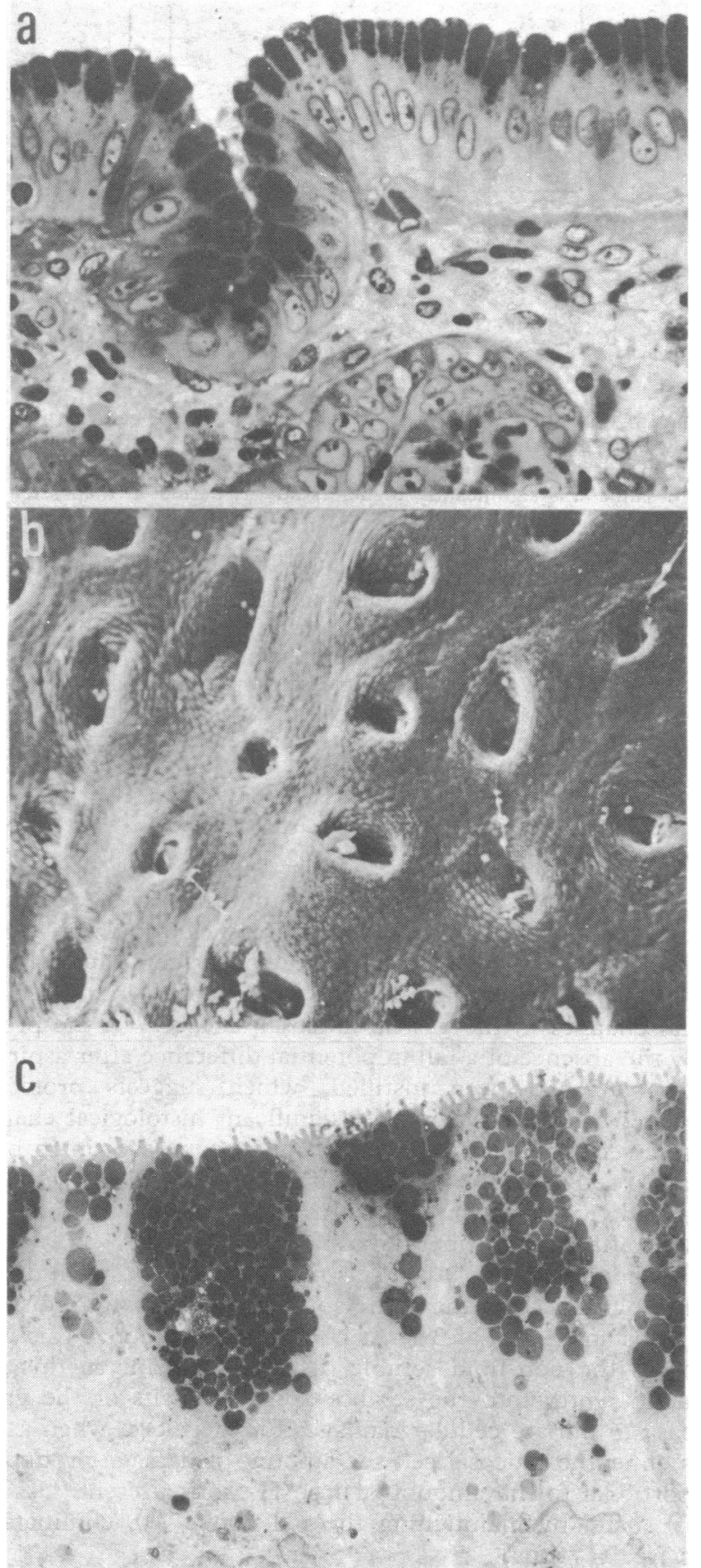

FIG 2-(a) Section of normal gastric mucosa from fundus under light microscopy (study 1, period 1). Note the one foveolae and underlying gastric glands. Apical portions of the normal surface epithelial cells contain dark-staining mucus. (Epon 812 section (Fisher Scientific Co, Fairlawn, New Jersey) toluidine blue. $\times 400$.) (b) Normal gastric mucosa as seen from mucosal surface by scanning electron microscopy. Several individual foveolae are evident as well as individual epithelial cell apices which give surface a cobblestone appearance. $(>200$.) (c) Transmission electron micrograph of normal surface mucosal cells 30 minutes after instillation of sodium bicarbonate. Note again intact epithelial cells with mucus granules. $(\times 500$.)
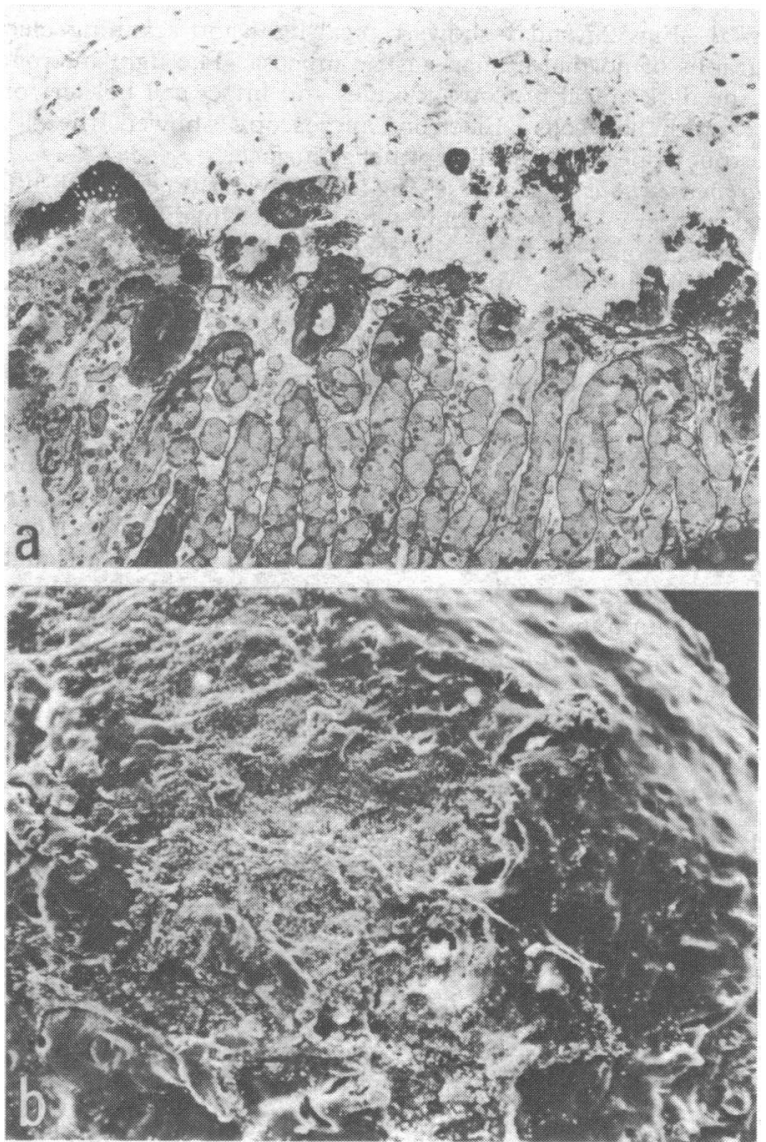

FIG 3-(a) Section of fundic gastric mucosa 10 minutes after instillation of aspirin (study 1, period 2). Example of microerosion of the mucosa. Damage is confined to the mucosa well above the muscularis mucosae. $(\times 100)(b)$ Mucosal surface of gastric erosion 10 minutes after instillation of aspirin as seen by scanning electron microscopy. Note gross morphological damage. $(\times 50$.

Specimen preparation-Specimens were prepared for light microscopy, transmission, and electron microscopy by techniques previously described. ${ }^{18-12}$ Each light microscopic section stained with toluidine blue was coded and read "blind" by a histopathologist. Cells were evaluated for damage by counting 1000 consecutive surface cells per section. Cells were recorded as damaged if they had nuclear or cytoplasmic changes, or both. ${ }^{1}$

Statistical analysis was performed with paired Student's $t$-test, with significance accorded at the 0.05 level. The $\gamma^{2}$ test was used for comparing the number of erosions between the aspirin in saline solution and the aspirin in bicarbonate solutions, with significance accorded at 0.05 level.

\section{Results}

\section{POTENTIAL DIFFERENCE STUDIES}

The mean value during the saline infusion $(-43.0 \pm 1.0 \mathrm{mV})$ was similar to that found in previous studies in man. After sodium bicarbonate instillation the potential difference rose to $-51.4 \mathrm{mV} \pm 1.6$ $(P<0.05)$. At each period there was much greater variation in potential difference during the bicarbonate instillation than during the saline infusion. This may have been due to artefacts produced by increased gastric emptying with a neutral intragastric $\mathrm{pH}$. There was no significant difference between potential difference values after sodium bicarbonate and those after aspirin with bicarbonate. Potential difference was significantly higher after aspirin in bicarbonate than after aspirin in saline: the sodium bicarbonate prevented the fall in potential difference caused by aspirin.

Acidity of gastric contents-The $\mathrm{pH}$ of aspirates with aspirin in saline decreased from $2 \cdot 3$ to 2.0 in 30 minutes while the $\mathrm{pH}$ of aspirates with aspirin in sodium bicarbonate showed no change from $\mathrm{pH} 7 \cdot 4$. 
LIGHT AND SCANNING ELECTRON MICROSCOPY

Normal-Figs $2 a$ and $b$ shows typical light and scanning electron micrographs of normal human gastric mucosa. The light micrograph shows the dark apical mucous granules and intact cell borders of the surface epithelial cells. Electron microscopy showed the typical cobblestone appearance of the epithelial surface.

Bicarbonate-induced changes-Fig $2 c$ shows the electron microscopical appearance of specimens taken after instillation of bicarbonate. Occasional surface cells seen on light microscopy showed mucous degranulation. Apart from this mucous degranulation, the rest of these cells (including the nucleus) appeared normal by light microscopy and transmission electron microscopy.

Changes induced by aspirin in saline-The considerable damage caused by aspirin in saline as seen by light and scanning electron microscopy is shown in fig 3 . Erosions such as these were seen in four of the five biopsy specimens taken 10 minutes after aspirin administration. Other changes seen in the surface epithelial cells are illustrated in fig 4. On light microscopy an appreciable number of surface cells showed a loss of toluidine-staining density of cytoplasm throughout the entire cell (fig $4 a$ ). The cytoplasm showed small clear vacuoles, along with clumping and margination of chromatin in the nuclei. Corresponding with this surface epithelial damage was the honeycombed appearance seen on scanning electron microscopy, which was due to cellular fall-out or focal loss of apical cell membranes (fig $4 b$ ).

Changes induced by aspirin in bicarbonate-Light microscopy showed normal-looking epithelial cells with only a few damaged ones, and there was only minimal honeycombing of the surface of the epithelial cells on scanning electron microscopy. No erosions were seen by either light or scanning electron microscopy.

Measuring of cell damage-Fig 5 shows the percentage of surface epithelial cell damage on light microscopy. Ten minutes after aspirin

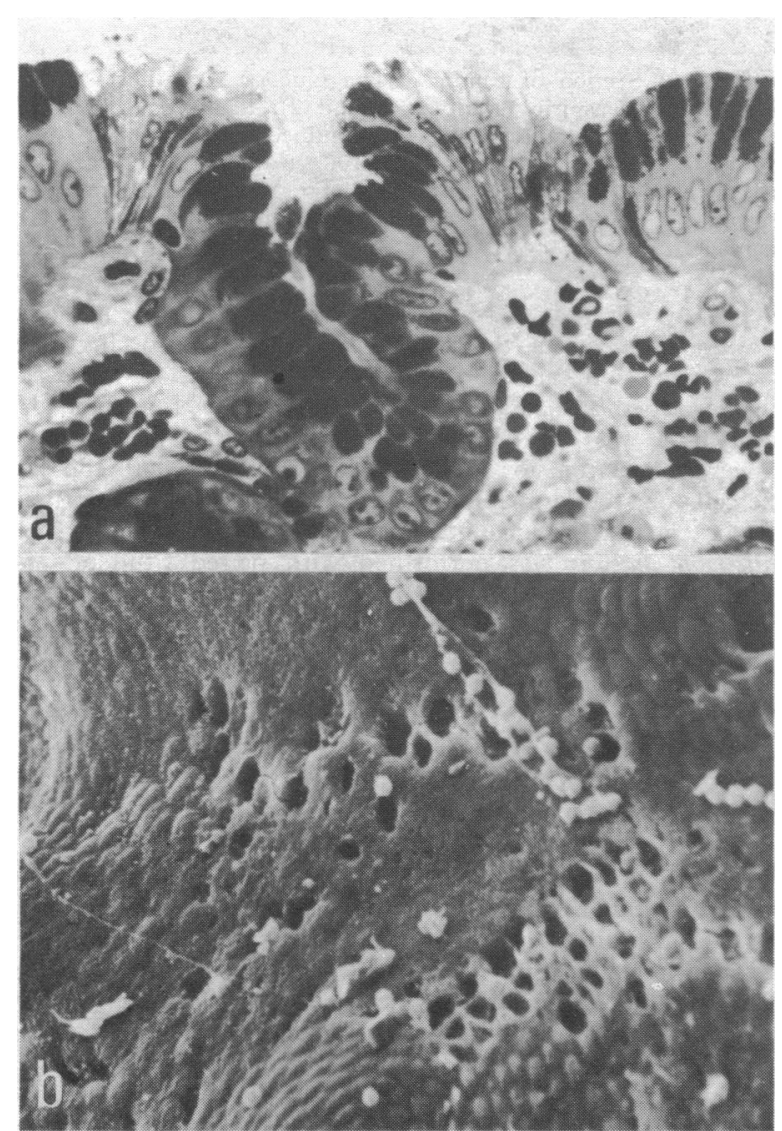

FIG 4-(a) Section of fundic gastric mucosa 10 minutes after instillation of aspirin. Damaged surface epithelial cells are largely confined to areas between foveolae. Mucus and cell debris are seen above surface of the severely damaged cells (Epon 812 section, toluidine blue stain. $(\times 400$. $)(b)$ Mucosal surface from fundic area 10 minutes after instillation of aspirin as seen by scanning electron microscopy. Note honeycombed appearance of surface due to localised foci of damaged surface cells. $(\times 500$. $)$

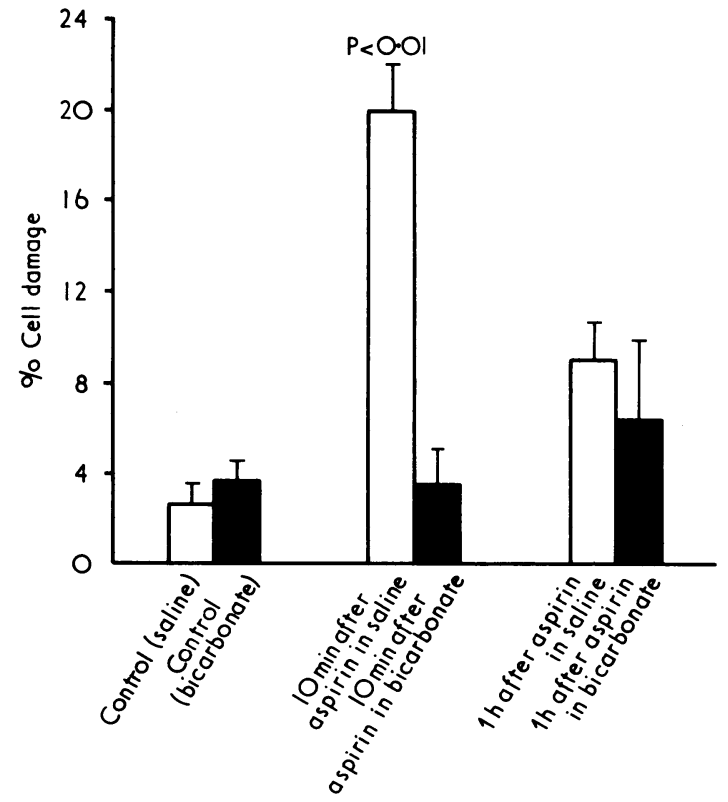

FIG 5-Bar graph of percentage of damaged surface cells as seen by light microscopy. Values shown are means $\pm \mathrm{SE}$ of mean. Number of cells damaged 10 minutes after instillation of aspirin in saline was significantly higher (study 1, period 2) than after aspirin in bicarbonate.

in saline was introduced into the stomach $20 \%$ of the surface cells were damaged, in addition to erosions. In contrast, only $3.4 \%$ of the cells were damaged 10 minutes after aspirin in bicarbonate was instilled $(P<0.01)$, and no erosions were present. The amount of damage in specimens taken 10 and 60 minutes after aspirin in bicarbonate was not significantly different from that in control specimens.

\section{Discussion}

$\mathrm{Rehm}^{13}$ was one of the first to point out that damage to gastric mucosa caused a fall in potential difference, which he termed an "injury potential." We have previously correlated the observed fall in potential difference with aspirin-induced histological changes in the gastric mucosal surface. ${ }^{1}$ In the present study the absence of a fall in potential difference after aspirin in bicarbonate had been instilled, which suggests protection, correlated with the absence of significant histological changes. As assessed by light and electron microscopy aspirin in bicarbonate produced insignificant damage compared with that produced by aspirin in saline. In particular, no erosions were present after aspirin in bicarbonate.

Bicarbonate probably protects mucosa against aspirin damage mainly by increasing the $\mathrm{pH}$. Aspirin is an acid with a dissociation constant $(\mathrm{pKa})$ of 3.5 . At $\mathrm{pH}$ values well above this $\mathrm{pH}$ it exists in the non-lipid soluble dissociated form. In this form it cannot enter into the surface epithelial cells of the gastric mucosa to initiate cellular damage. Furthermore, when aspirin does enter the mucosal cell the amount of damage produced is proportional to the amount of free $\mathrm{H}^{+}$ions present. ${ }^{1415}$ Thus bicarbonate, by maintaining the $\mathrm{pH}$ above $7 \cdot 0$, eliminates all such free $\mathrm{H}^{+}$ions.

There are two other possible mechanisms ${ }^{16}{ }^{17}$ by which the neutral $\mathrm{pH}$ of the aspirin and bicarbonate solution may protect against aspirin damage. Firstly, at this $\mathrm{pH}$ the aspirin particles are completely dissolved to form a solution. Aspirin is relatively poorly soluble in water or saline (about $300 \mathrm{mg}$ dissolves in $100 \mathrm{ml}$ water) so that $600 \mathrm{mg}$ (two tablets) forms a suspension of aspirin particles. Aspirin particles have been shown to form erosions in other parts of the gastrointestinal tract independent of $\mathrm{pH}$-for example, in the mouth. ${ }^{18}$ Secondly, the increased $\mathrm{pH}$ of the gastric contents would tend to increase gastric empty- 
ing, thus decreasing contact time between the aspirin solution and gastric mucosa.

Of two commercially available preparations of buffered aspirin, Bufferin contains only $3 \mathrm{mmol}(\mathrm{mEq}$ ) of bicarbonate in the amount of aspirin used in this study while Alka-Seltzer contains two and a half times the amount of buffer used-that is, about $45 \mathrm{mmol}$ bicarbonate per $728 \mathrm{mg}$ sodium salicylate. Thus Bufferin almost certainly contains too little buffer to protect against aspirin damage while Alka-Seltzer contains enough to do so. Nevertheless, Alka-Seltzer contains other ingredients and is a hyperosmotic solution $\left(\mathrm{Na}^{+}\right.$concentration $280 \mathrm{mmol} / \mathrm{l}$; osmotic pressure $590 \mathrm{mmol}(\mathrm{mOsm}) / \mathrm{kg}$ ), so its effects on gastric mucosal histology need to be tested separately. Interestingly, Alka-Seltzer raises the potential difference in man over values produced by saline. ${ }^{19}$

Although the increase in potential difference produced by sodium bicarbonate is interesting, the mechanism of the increase cannot be determined from this study. It may be related to changes in the distribution of $\mathrm{Na}^{+}, \mathrm{Cl}^{-}$, or $\mathrm{H}^{+}$ions, all of which may affect potential difference. ${ }^{20}$ Nevertheless, we can conclude that aspirin adequately buffered with sodium bicarbonate prevents both the aspirin-induced fall in potential difference and histological damage caused by aspirin.

A paper based on this work was presented at the annual meeting of the American Gastroenterological Association, Toronto, Canada, May 1977. The work was supported in part by the Medical Research Service of the Veterans Administration, grants from the American Gastroenterological Association, and the patient study facilities of the UMMC Clinical Research Center.

Requests for reprints should be addressed to: Dr Kevin J Ivey,
University of Missouri, Department of Medicine, Columbia, Missouri 65201.

\section{References}

${ }^{1}$ Baskin, W N, et al, Annals of Internal Medicine, 1976, 85, 299.

2 Davenport, H W, American Fournal of Digestive Diseases, 1976, 21, 141.

Thorsen, W B, Western, D, Tanaka, Y, et al, Archives of Internal Medicine, 1968, 121, 499.

${ }^{4}$ Wood, P H N, Harvey-Smith, E A, and Dixon, A St J, British Medical fournal, 1962, 1, 669.

5 Stubbe, L T F L, Pietersen, J H, and Van Heulen, C, British Medical fournal, 1962, 1, 675 .

${ }^{6}$ Andersson, S, and Grossman, M I, Gastroenterology, 1965, 49, 364.

' Fordtran, J S, Morawski, S G, and Richardson, C T, New England Journal of Medicine, 1973, 288, 923.

${ }^{8}$ Millonig, G, Fournal of Applied Physics, 1961, 32, 1637.

${ }^{9}$ Watson, M L, fournal of Biophysical and Biochemical Cytology, 1958, 4, 475.

${ }^{10}$ Reynolds, E S, fournal of Cell Biology, 1963, 17, 208.

${ }^{11}$ Meller, S M, et al, Anatomical Record, 1973, 176, 245.

12 Krause, W J, and Leeson, C R, American fournal of Anatomy, 1973, 137, 337.

${ }_{13}$ Rehm, W R, American fournal of Physiology, 1944, 140, 720.

${ }^{14}$ Ivey, K J, Medical Clinics of North America, 1974, 58, 1289.

${ }^{15}$ Ivey, K J, Baskin, W, and Jeffrey, G, Lancet, 1975, 2, 1072.

${ }^{16}$ Leonards, J R, and Levy, G, Fournal of Pharmaceutical Sciences, 1969, 58, 1277.

17 Davenport, H W, Gastroenterology, 1966, 50, 487.

${ }_{18}$ Roth, J L A, et al, Gastroenterology, 1963, 44, 146.

${ }^{19}$ Murray, H S, Strottman, M P, and Cooke, A R, British Medical fournal, 1974, 1, 19.

${ }^{20}$ Ivey, K J, Gastroenterology, 1971, 61, 247.

(Accepted 15 August 1977)

\title{
Survivors of ruptured abdominal aortic aneurysm: the iceberg's tip
}

\author{
ROGER H ARMOUR
}

British Medical fournal, 1977, 2, 1055-1057

\begin{abstract}
Summary
In four and a half years 25 patients in one community suffered a ruptured abdominal aortic aneurysm. Eleven died at home, nine died without operation in hospital, and only five had the aneurysm removed. There were four survivors. A further seven patients might have lived had they had a prompt operation. The average operative mortality for ruptured aneurysms among series reported in British journals is $53 \%$, but the survivors are a small minority of the total number of people in the community whose aneurysms rupture. No basis could be found for the view that replacing an aortic aneurysm with a straight graft (while leaving behind aneurysmal common iliac arteries) lowers the operative mortality. On the contrary, oversimplifying the operation may be hazardous.
\end{abstract}

Lister Hospital, Stevenage, Herts SG1 4AB

ROGER H ARMOUR, FRCS, MRCP, consultant surgeon

\section{Introduction}

In 1965 Turk $^{1}$ suggested that only a small proportion of patients with a ruptured abdominal aortic aneurysm received surgical treatment. His paper attracted little interest. Most surgeons have concentrated on trying to improve treatment, and it has recently been claimed that replacement of the aneurysm with a straight tube graft instead of the more usual bifurcation graft lowers the operative mortality."

I decided to investigate the effect of surgery on the mortality of ruptured aneurysms in the community and to examine the hypothesis that straight tube grafts are best.

\section{Patients and methods}

The records of patients who were treated for or died from a ruptured atherosclerotic abdominal aortic aneurysm in north Hertfordshire from 1 September 1972 (when the Lister Hospital opened) to 28 February 1977 were studied. The 500-bed hospital serves a population of 175000 .

The diagnosis was made at operation or necropsy (22 patients) or on clinical grounds (three patients). There was a single, fatal, example of a ruptured, dilated, atherosclerotic common iliac artery which was included in the series, but dissecting and mycotic aneurysms were not.

Operative technique-Patients who had the aneurysm resected were resuscitated with isotonic saline before operation. A midline abdominal incision was made, the posterior peritoneum was opened, and after dissecting through the retroperitoneal haematoma a vascular 